\title{
Study, Manufacturing and Analysis of Conveyor Chain Pin by using Composite Material
}

\author{
A.M. Khandekar, G.R. Mote, N.S. Vastre, S.A. Mosalgi, S.B. Bhosale
}

\begin{abstract}
Carbon fibers are fibers about 5-10 micro meters in diameter and composed mostly of carbon atoms. Carbon fibers have several advantages including high stiffness, high tensile strength, low weight, high chemical resistance, high temperature tolerance and low thermal expansion. These properties have made carbon fiber very popular in aerospace, civil engineering, military, and motorsports, along with other competition sports. However, they are relatively expensive when compared with similar fibers, such as glass fibers or plastic fibers. Carbon fibers are usually combined with other materials to form a composite. When impregnated with a plastic resin and baked it forms carbon-fiber-reinforced polymer (often referred to as carbon fiber) which has a very high strength-to-weight ratio, and is extremely rigid although somewhat brittle. Carbon fibers are also composited with other materials, such as graphite, to form reinforced carbon-carbon composites, which have a very high heat tolerance. Carbon fibers are the strongest fibers currently available to reinforce polymeric matrices. High performance grade carbon fibers display tensile strength exceeding $6 \mathrm{GPa}$ and tensile modulus exceeding 600GPa. Coupled with their low-density (1.8 -2.0 $\mathrm{g} / \mathrm{cm} 3$ ), carbon fibers possess the highest specific stiffness and strength, and find extensive use in aerospace grade composites.

Index Terms - Carbon fibers, carbon-fiber-reinforced polymer, convey chain, tensile strength.
\end{abstract}

\section{INTRODUCTION}

We did the survey of many sugar industry. As per this survey it is observed that sugar industries are facing problem of conveyor chain pin failure. In this type of chain failure is mainly happening due to failure of pin, which causes huge loss to industry and indirectly it effects on economic growth of nation. Most of the times pin is under tension which causes failure of chain. Causes of this failure are improper design, improper material selection and Uncertainties in manufacturing. So we decided that replace the current pin by the composite material (carbon fiber of 300GSM).FarhadAhmadijokani et.al [1] prepared the composite brake friction material containing carbon fiber at

Gopal R Mote, Mechanical Engineering, Sveri's College of Engineering Pandharpur, Pandharpur, India.

Akshay M Khandekar, Mechanical Engineering, Sveri's College of Engineering Pandharpur, Pandharpur, India

Nagesh S Vastre, Mechanical Engineering, Sveri's College of Engineering Pandharpur, Pandharpur, India

Shrikant A Mosalgi, Mechanical Engineering, Sveri's College of Engineering Pandharpur, Pandharpur, India

S.B.Bhosale, Assistant Professor, Mechanical Engineering, Sveri's College of Engineering Pandharpur, Pandharpur, India various concentrations and investigated the effect of short carbon fiber on tribological behavior of phenolic based friction materials.

AsmaEddib et.al [2] provides the first determination of permittivity of continues carbon fiber and measurement is conducted along fiber axis by capacitance measurement. Parvezoelemet.al [3] worked on cyclic loading, fatigue failure, service life, damage tolerances of component and joint. Jaun Naranjo et.al [4] presents evaluation of the effects that different geometry parameters have on the tensile properties of 3D printed composites. Guanxia Yang et.al [5] shows that highest bonding strength could be achieve when the surface was sanded in the random direction. Masashi Wada et.al [6] Studied thermal analysis of carbon fiber reinforced sheet with the help of superheated steam and he compared obtained results with the tensile properties of recycled carbon fiber. Andrew Dickson et.al [7] Studied nylon coated carbon fiber in the form of filaments in this paper examines an additive manufacturing techniques for the fabrication of composites. S. G. Sapateet.al [8] showed non uniformity in the induction hardening and undesirable course martensitic structure at the core. J.D. Bressanet.al [9] did wear test by sliding abrasion were in a pin-on disc tribometer and he concluded wear resistance varies substantially because of different hardness. YehiaElmogahzyet.al [10] focused on the tensile behavior of carbon fiber which deals with the different methods of static tensile testing. Bo Dong et.al [11] observed the tensile properties of fiber are of high significance for composite material. B. Z. Haque et.al [12] told the crashworthiness of a high performance composite structure is associated to its energy absorption capacity through controlled failure mechanism during an impact or crush and compression testing. Filip Stojcevski et.al [13] studied the surface treatments improve interfacial adhesion of carbon fiber composites however little research examines the translatability of interfacial shear strength (IFSS) across testing scales. NurainHashimaet.al [14] studied the Effect of fiber orientation on tensile and low cycle fatigue of interplay hybrid composites was investigated. Pui-Yan Hung et.al [15] explains that carbon fiber is extremely strong, contributing to a thin, light but strong structure. Yoshihiro Sawada et.al [16] concluded that the tensional modulus decreases with increasing Young's modulus for carbon fibers. G.Viguiet.al [17] determined the modulus of elasticity of different composite resin materials. D Coen, P Mondello [18] studied conveyor chain for conveying products comprises a plurality of links. E Ramsey [19] Studied two piece pivot chain link which through its construction allows the top platform piece to be removable, replaceable, additionally the pin attachment. $\mathrm{T}$ Takahashi et.al [20] invented a molded conveyor chain 
having number of link plates of synthetic resin pivotally connected together by connecting pin.

\section{MATERIALS AND MANUFACTURING}

\section{A. Review Stagestudy of conveyor chain}

Conveyor chain is most commonly used for conveying various materials in many kinds of domestic, industrial and agricultural machinery, including conveyors, wire and tube drawing machines, printing presses. It consist of a series forged links connected by pin joints. It is driven by a toothed wheel called a sprocket. It is a simple, reliable and efficient means of conveying purpose.

\section{B. Final Stagestudy of carbon fiber}

Carbon Fiber is a polymer and is sometimes known as graphite fiber. It is a very strong material and light in weight. Carbon fiber is five-times stronger than steel and twice as stiff. Carbon fiber is made of thin, strong crystalline filaments of carbon that is used to strengthen material. Carbon fiber can be thinner than a strand of human hair and gets its strength when twisted together like yarn. Table 1, Table 2 and Table 3 shows mechanical properties of carbon fiber, epoxy resign and composite respectively.

Table 1.Mechanical properties of carbon fiber

\begin{tabular}{|c|c|c|c|c|}
\hline Product & $\begin{array}{c}\text { Design tensile } \\
\text { strength }(\mathrm{GPa})\end{array}$ & $\begin{array}{l}\text { Density } \\
(\mathrm{Kg} / \mathrm{m} 3)\end{array}$ & $\begin{array}{l}\text { Elongation } \\
\text { at break } \\
(\%)\end{array}$ & $\begin{array}{l}\text { Tensile } \\
\text { strength } \\
(\mathrm{GPa})\end{array}$ \\
\hline $\begin{array}{c}\text { Carbon } \\
\text { fiber }\end{array}$ & 3.79 & 1740 & 1.7 & 230 \\
\hline
\end{tabular}

Table 2.Mechanical properties of epoxy resin

\begin{tabular}{|c|c|c|c|c|}
\hline Product & $\begin{array}{l}\text { Compressive } \\
\text { strength(MPa) }\end{array}$ & $\begin{array}{l}\text { Density } \\
(\mathrm{Kg} / \mathrm{m} 3)\end{array}$ & $\begin{array}{l}\text { Bending } \\
\text { strength } \\
(\mathrm{MPa})\end{array}$ & $\begin{array}{l}\text { Tensile } \\
\text { modulus } \\
(\mathrm{MPa})\end{array}$ \\
\hline $\begin{array}{c}\text { Epoxy } \\
\text { resin }\end{array}$ & 88 & 1160 & 80 & 2800 \\
\hline
\end{tabular}

Table 3.Mechanical properties of carbon fiber and epoxy resin

\begin{tabular}{|l|l|l|l|l|}
\hline Product & $\begin{array}{l}\text { Design } \\
\text { tensile } \\
\text { strength } \\
(\mathrm{MPa})\end{array}$ & $\begin{array}{l}\text { Thickness } \\
(\mathrm{mm})\end{array}$ & $\begin{array}{l}\text { Elongation } \\
\text { at break } \\
(\%)\end{array}$ & $\begin{array}{l}\text { Tensile } \\
\text { modulus } \\
(\mathrm{MPa})\end{array}$ \\
\hline Comp. & 745 & 1.0 & 1.0 & 61.5 \\
\hline
\end{tabular}

\section{Manufacturing steps}

Following are the manufacturing steps of composites Step 1: Cutting carbon fiber in to required shape.

Step 2: Mixing of araldite and hardener.

Step 3: Use of silicon fiber to remove support easily and make pin hollow.

Step 4: Apply mixture of araldite and hardener on carbon fiber sheet and roll on support.

Step 5: Keep it for two days for drying.

When we purchased the material which was in the form of square sheet, for manufacturing of pin we cut it into required shape by using cutter and scale according to dimensions. Then we took the hardener and epoxy resin. For getting proper strength we mix the hardener and epoxy in the proportion of 1:10. We used stirrer for proper mixing of same. After this take a sheet of carbon fiber on plane surface and apply the mixture on complete sheet with the help of brush. After this take supporting rod and apply the silicon spray on it to avoid sticking carbon sheet and easy removal. Then put the rod on sheet and roll slowly with constant feed so that proper shape can be achieved. Keep it for drying near about 48 hours. After proper drying remove the supporting rod. Then cut the unwanted part. Finally the pin is ready for testing.

\section{RESULT AND DISCUSSION}

The prepare specimens were tested for tensile strength using UTM machine (UTK-100E (PC) SR.NO.2011/14 74) of capacity $1000 \mathrm{KN}$. The figure 1 shows the experimental set up during testing.

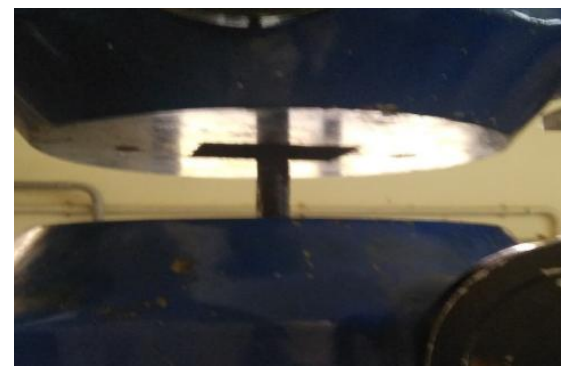

Figure 1. Tensile testing of composite specimens

The variation in tensile strength with no of layers has been shown in Figure 2. The highest tensile strength of $54.5 \mathrm{KN}$ was observed at 20 layers composite while lowest tensile strength of $12.1 \mathrm{KN}$ was recorded at 5 layers composite. This trend was observed due to increase in no of layers resulted in increase in tensile strength of composite.

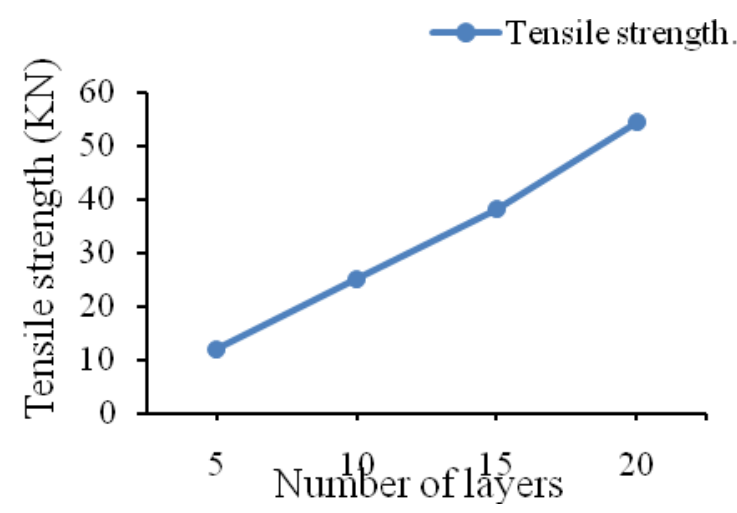

Figure 2. Variation in tensile strength

\section{CONCLUSION}

By analysing manufacturing process and result obtained it is concluded that tensile strength of conveyor chain is high as compared to previous material and it is mainly depend on number of layers of carbon fiber and quantity of epoxy used. If we replce manual rolling with automatic rolling and if we increse number of carbon layers with proper quantity of epoxy then definatly tensile strength will increase.

\section{ACKNOWLEDGMENT}

This work is just not an individual contribution till its completion we take this opportunity to thank all for bringing 
it close to the conclusion. Mr. Akshaylaulkar for accepting our studentship, and continuously assessing our work and providing great guidance by timely suggestions and discussions at every stage of this work.We also thankful to Dr. N. D. Misal and Prof. Y. D. chavan for providing testing facility and supporting to us.

\section{REFERENCES}

[1] FarhadAhmadijokani,YasamanAlaei,Akbar Shojaei, Mohammad Arjmand, NingYan, (2019) Frictional behavior of resin-based brake composites: Effect of carbon fiber reinforcement, Wear, 420-421,108-115.

[2] Asmaeddib, chung, (2019) Electric permeability of carbon fiber, carbon, 143,475-480.

[3] Parvezoalem, colinrobert (2019) the fatigue failure of carbon fiber reinforced plastic. Composites part B: Engineering, 166, 555-579.

[4] Juan Naranjo, Wilco M.H. verbeeten, Horacio Ahuett-Garza, PedroOrata-castanon, (2019) Tensile properties and failure behavior of chopped and continuous carbon fiber by additive manufacturing, Additives manufacturing, 26,217-241.

[5] Guanxia yang, Tao yang (2019) the influence of surface treatment on the tensile properties of carbon fiber reinforced epoxy composite bonded joints, 160, 446-456.

[6] Masashi Wada, Isamu Ohsawa, Satoshi Kitaoka, Jun Takahashi(2018) Influence of treatment with superheated steam on tensile properties of carbon fiber, Composite part A: Science and manufacturing, 107, 555-560.

[7] Andrew dickson, denisdowling, (2019) Enhancing the bearing strength of carbon fiber thermoplastic composite through additive manufacturing, Composite structure, 212, 381- 388

[8] S.G. Sapate, V.K. Didolkar (2009) Metallurgical investigation failure of coal mill drag chain pin, Materials and design 30, Issue 7 , 2623-2629.

[9] J.D. Bressan, D. P. Daros, A Sokolowoski, R Mesquita (2008) Influence of hardness on the wear resistance of 17-4 PH stainless steel evaluated by the pin- disc testing, Journals of materials processing technology 205, Issues 1-3,353-359.

[10] YehiaElmogahzy (2018) Handbook of properties of Textile and Technical Fiberes (second Edition) "The textile institute book series, 223-273.

[11] Bo Dong, Long Tian, Bing Pan (2019) Tensile Testing Of Carbon Fiber Multifilament Using an advanced video extensometer assisted by dual reflector imaging, 138,325-331.

[12] R.M.DiBendetto, B.Z. Haque, M. A. Ali, (2013) Energy absorption study consideration crush test on carbon fiber /epoxy and carbon fiber /polyurethane structural composite beams. Composite structure, 203 , 242-253.

[13] Filip Stojcevski, Timothy B. Hilditch, Luke C. Henderson, A comparison of interfacial testing methods and sensitivities to carbon fiber surface treatment conditions Composite part A: Applied science and manufacturing, 118, 293-301.

[14] NurainHashima ,Dayang Laila , Abdul Majida .El-SadigMahdib ,RizalZaharia,Noorfaizal, (2019) Effect of fiber loading directions on the cycle fatigue of intraply carbon-Kevlar reinforced epoxy hybrid composites, Composite structures, 212, 476-483.

[15] Pui-yan Hung, Kin-tak Lau, Lai-kwan Cheng, JinsongLeng, David Hui, (2018) Impact response of hybrid carbon/glass fibre reinforced polymer composites designed for engineering applications, Composites Part B: Engineering, 133, 86-90.

[16] Yoshihiro Sawada, Akio Shindo, (1992) Torsional properties of carbon fibers, Carbon, 30, Issue 4,619-629.

[17] G. Viguie, G. Malquarti, B. Vincent, and D. Bourgeois, (1994) Epoxy/carbon composite resins in dentistry: Mechanical properties related to fiber reinforcements, The Journal of Prosthetic Dentistry, 72, Issue 3,245-249.

[18] Coen, D., \&Mondello, P. (2001). U.S. Patent No. 6,250,459. Washington, DC: U.S. Patent and Trademark Office.

[19] Ramsey, E. (2002). U.S. Patent No. 6,347,699. Washington, DC: U.S. Patent and Trademark Office.

[20] Takahashi, T., Shibayama, K., Murakami, Y., \& Ishii, T. (2001). U.S. Patent No. 6,213,292. Washington, DC: U.S. Patent and Trademark Office. 